\title{
Peer-reviewed abstracts from the 2014 Student Poster Contest
}

\author{
Minerals and Metallurgical Processing Division \\ Society for Mining, Metallurgy \& Exploration Inc. \\ February 26, 2014, Salt Lake City, UT
}

Foreword by Emily Sarver
Assistant professor, Mining and Minerals Engineering, Virginia Tech, Blacksburg, VA

The Mineral Processing Division hosted its fifth Student Poster Contest during the 2014 SME Annual Meeting and Exhibit in Salt Lake City, UT - and, by all accounts, it was a huge success! This year, the contest more than doubled in numbers of individual entries and schools represented. A total of 30 students participated, including 23 graduates and 7 undergraduates, representing 13 US and international institutions: Colorado School of Mines, Michigan Tech, Missouri University of Science and Technology, Montana Tech, New Mexico Tech, South Dakota School of Mines, University of Kentucky, University of Utah, Virginia Tech, West Virginia University, Autonomous University of Chihuahua (Mexico), UNAL Medellin (Colombia), University of British Columbia (Canada). In addition to constructing their posters, students submitted abstracts and gave short oral presentations highlighting their research. Based on tallied scores from all three components of the contest, the judging panel selected 1st, 2nd and 3rd place winners at the undergraduate and graduate levels, which were announced during the MPD Luncheon on February 26.

In the undergraduate division, University of Utah's Lucas Pich was awarded the 1st place prize for his poster "Solid-liquid mixing studies in lab-scale flotation tank using electrical resistance tomography." His extended abstract is included in this issue of Minerals \& Metallurgical Processing. Joshua Chidester, also of Utah, won 2nd place for his poster presenting "Evaluation of detectors for radiotracer RTD measurement by MCNP." And Lucas Rojas-Mendoza, of UNAL Medellin, took 3rd place for his poster on "Preg-robbing in Colombian gold ores."

In the graduate division, 1st place went to Caelen Anderson, of the Colorado School of Mines, who also placed in this contest in 2012 and 2013! The 2nd and 3rd place prizes were awarded to Jacob McDonald and Joseph Halt, respectively, both of Michigan Tech. Extended abstracts describing the work of these up-and-coming researchers are also included in this issue.

The 2014 Contest was chaired by Emily Sarver (Virginia Tech) and Lisa Schlink (Freeport-McMoran Copper and Gold, Inc.). Aaron Noble (West Virginia University), David Perkins (Derrick Corporation) and Derek Novotny (Eriez) graciously served on the judging panel this year.

Special thanks are extended to all sponsors of the 2014 MPD Student Poster Contest, and to all student participants. Please watch for upcoming details on the 2015 Contest. We look forward to seeing you in Denver!

The Mineral and Metallurgical Processing Division of SME was able to sponsor this contest thanks to the generous support of the companies that sponsored the MPD 2014-2015 calendar.

$\begin{array}{ll}\text { - } & \text { ABB } \\ \text { - } & \text { BASF } \\ \text { - } & \text { Cardero } \\ \text { - } & \text { Cytec } \\ \text { - } & \text { Eriez } \\ \text { - } & \text { FLSmidth }\end{array}$

Hazen Research

Kappes, Cassiday \& Associates

M3 Engineering

Polysius Corp

Tetra Tech

Sepor 